\title{
SEASONAL VARIATION OF PLANKTONIC FUNGAL COMMUNITY STRUCTURE IN THE XIJIANG RIVER, CHINA
}

\author{
LIU, Q. F. ${ }^{1,2}-$ LAI, Z. N. ${ }^{1,2^{*}}-$ WANG, C. ${ }^{1,2}-$ ZHANG, D. F. ${ }^{1,2}-$ MAI, Y. Z. ${ }^{1,2}-$ DU, H. ${ }^{3}$ \\ ${ }^{1}$ Pearl River Fisheries Research Institute, Chinese Academy of Fishery Sciences, Guangzhou \\ 510380, China \\ (first author:liuqfwh@163.com) \\ ${ }^{2}$ Fishery Ecological Environment Monitoring Center of Pearl River Basin, Ministry of \\ Agriculture and Rural Affairs, Guangzhou 510380, China \\ ${ }^{3}$ Key Lab of Freshwater Biodiversity Conservation Ministry of Agriculture and Rural Affairs, \\ Yangtze River Fisheries Research Institute, Chinese Academy of Fishery Sciences, Wuhan \\ 430223, China \\ ${ }^{*}$ Corresponding author \\ e-mail:znlai01@163.com
}

(Received 25 $5^{\text {th }}$ Dec 2020; accepted $3^{\text {rd }}$ Mar 2021)

\begin{abstract}
To investigate the composition variation of planktonic fungal communities, and their relationship with water physical and chemical parameters in the Xijiang River in China, the compositions of planktonic fungal communities in the high-water and low-water period of the Xijiang River were studied in this paper by high-throughput sequencing of fungal internal transcribed spacer amplicons. Ascomycota, Basidiomycota, Chytridiomycota, Glomeromycota, Rozellomycota, and Zygomycota were detected from the planktonic fungal communities. However, most high-quality sequences $(59.58 \pm 0.03 \%)$ could not accurately identify fungal phyla. Alpha-diversity indexes of the fungal communities and the relative abundances of Phoma brasiliensis, Pseudozyma sp., Psathyrella sp., Haematonectria haematococca, Podoscypha sp. in the high-water period were significantly higher than those in the low-water period, while the relative abundances of Basidiobolus sp., Rhizophydium littoreum, Teratosphaeria jonkershoekensis, Malassezia globosa, Malassezia restricta, Malassezia sp., Alternaria eichhorniae, Knufia epidermidis, and Scedosporium prolificans were significantly lower. No significant correlation has been found between the fungal community distance and geographical distance along the river. Water temperature and dissolved oxygen significantly influenced the fungal community structure in the high-water period. These results provide information for us to understand the composition and influencing factors of the planktonic fungal community in rivers.
\end{abstract}

Keywords: subtropical fungal community, riverine, water ecosystem, high-throughput sequencing, internal transcribed spacer, physical and chemical parameters

\section{Introduction}

Fungal community plays an important role in maintaining the normal operation of water ecosystems (Cai et al., 2006). Aquatic fungi decompose organic matter and promote nutrient migration, which cooperate with protozoa to utilize aquatic nutrients and promote the flow of material and energy in water ecosystems (Grattan and Suberkropp, 2001; Gulis and Suberkropp, 2003; Chung and Suberkropp, 2008; Röske et al., 2012; Zhang et al., 2013). These roles have been demonstrated for planktonic fungal communities (Gao et al., 2010; Gutierrez et al., 2011; Kagami et al., 2012). However, despite the fact that the composition and function of fungal communities in soil (Broeckling et al., 2008; Mueller et al., 2015; Carson et al., 2019; Lance et al., 2020), sediment (Wu et al., 2013; Sui et al., 2016; Wang et al., 2018a), ocean (Gao et al., 2010; Gutierrez et al., 2011), lake 
(Kagami et al., 2012), reservoir (Shang et al., 2018; Chen et al., 2018) and other ecosystems have been widely studied, the research on fungal communities in river water ecosystems is very scarce (Bärlocher and Boddy, 2016).

The river ecosystem is one of the most important ecosystems on earth, and its ecological function is of great concern (Hopkins et al., 2011). Rivers are the primary conduits for land-to-ocean transfer of materials including terrestrial organic matter, nutrients, and anthropogenic pollutants. Microbial communities in rivers, estuaries, and plumes regulate the nutrient concentrations and biogeochemistry of these river-borne materials and mediate their impact on carbon cycling. Although the compositions of prokaryotic communities in rivers and their variation with physical and chemical factors and seasons were investigated (Maksimenko et al., 2008; Kent and Bayne, 2010; Kaevska et al., 2016; Wang et al., 2018b), the composition of fungal communities in river ecosystems is rarely studied.

The Xijiang River is the mainstream of the Zhujiang (Pearl) River, which lies in a subtropical monsoon area, South China. It is $353,120 \mathrm{~km}^{2}$ of area and $230 \times 10^{9} \mathrm{~m}^{3}$ of annual runoff. The period from April to September is the flood season (Gao et al., 2002). The Xijiang River is rich in river water and bait resources, and the ecological environment is suitable for the growth of fish, shrimp, crab, and shellfish. It is rich in fish resources, with 136 fish species. It is an important habitat and breeding ground of aquatic organisms in subtropical areas ( $\mathrm{Li}$ et al., 2009, 2010). To investigate the composition and variation of planktonic fungal communities between the high-water and low-water periods, and their relationship with water physical and chemical parameters, in the present study, the compositions of planktonic fungal communities in the high-water and low-water period of Xijiang River in China were studied by high-throughput sequencing of fungal ITS gene amplicons on the Illumina HiMeq platform.

\section{Materials and Methods}

\section{Sampling collection}

Surface water samples were collected in March (low-water period) and June (high-water period) of 2017 from 13 sites in the Xijiang River (Fig. 1) using previously described methods with minor modifications (Yu et al., 2015). Briefly, triplicate water surface samples (approximately $0.5 \mathrm{~m}$ below water surface) were collected from each site using a 5 L Niskin bottle, mixed, and immediately stored in EPR-5590 sterile sampling bags (LABPLAS, Canada). The water samples were subsequently transferred to the laboratory on ice. $500 \mathrm{ml}$ water from each sample was filtered with $0.22 \mu \mathrm{m}$ pore size polycarbonate membranes (Millipore, USA), and the filters were stored at $-80{ }^{\circ} \mathrm{C}$ until DNA extraction. Other water samples were used to determine water physical and chemical parameters.

\section{Determination of water physical and chemical parameters}

Water transparency was field measured according to a standard method (Huang, 2000; $\mathrm{Ni}$ et al., 2010). Water temperature (WT, ${ }^{\circ} \mathrm{C}$ ), $\mathrm{pH}$, dissolved oxygen (DO, mg/L), oxidation-reduction potential (ORP, mv), conductivity (Cond, $\mu \mathrm{S} / \mathrm{m}$ ), and total dissolvable solid (TDS, g/L) were field measured using a ProQuatro smart portable multiparameter water quality analyzer (YSI, USA). Approximately $500 \mathrm{ml}$ water was filtered by WHATMAN GF/C filter membrane and used to measure the chlorophyll-a content 
(Chla, $\mu \mathrm{g} / \mathrm{L}$ ) according to a previously described method (The State Environmental Protection Administration, 2002). Concentrations of $\mathrm{NH}_{4}{ }^{+}-\mathrm{N}, \mathrm{NO}_{3}^{-}-\mathrm{N}, \mathrm{NO}_{2}^{-}-\mathrm{N}, \mathrm{TN}, \mathrm{TP}$, and $\mathrm{SiO}_{3}{ }^{2-}-\mathrm{Si}$ were determined using a SKALAR flow injection water quality analyzer (SKALAR Analytical, Netherlands) according to the manufacturer's instructions. Concentration of un-ionized ammonia $\left(\mathrm{NH}_{3}, \mathrm{mg} / \mathrm{L}\right)$ was calculated by $\mathrm{NH}_{4}{ }^{+}-\mathrm{N}, \mathrm{pH}$, and WT according to a previously described method (Zou and Cheng, 2002).

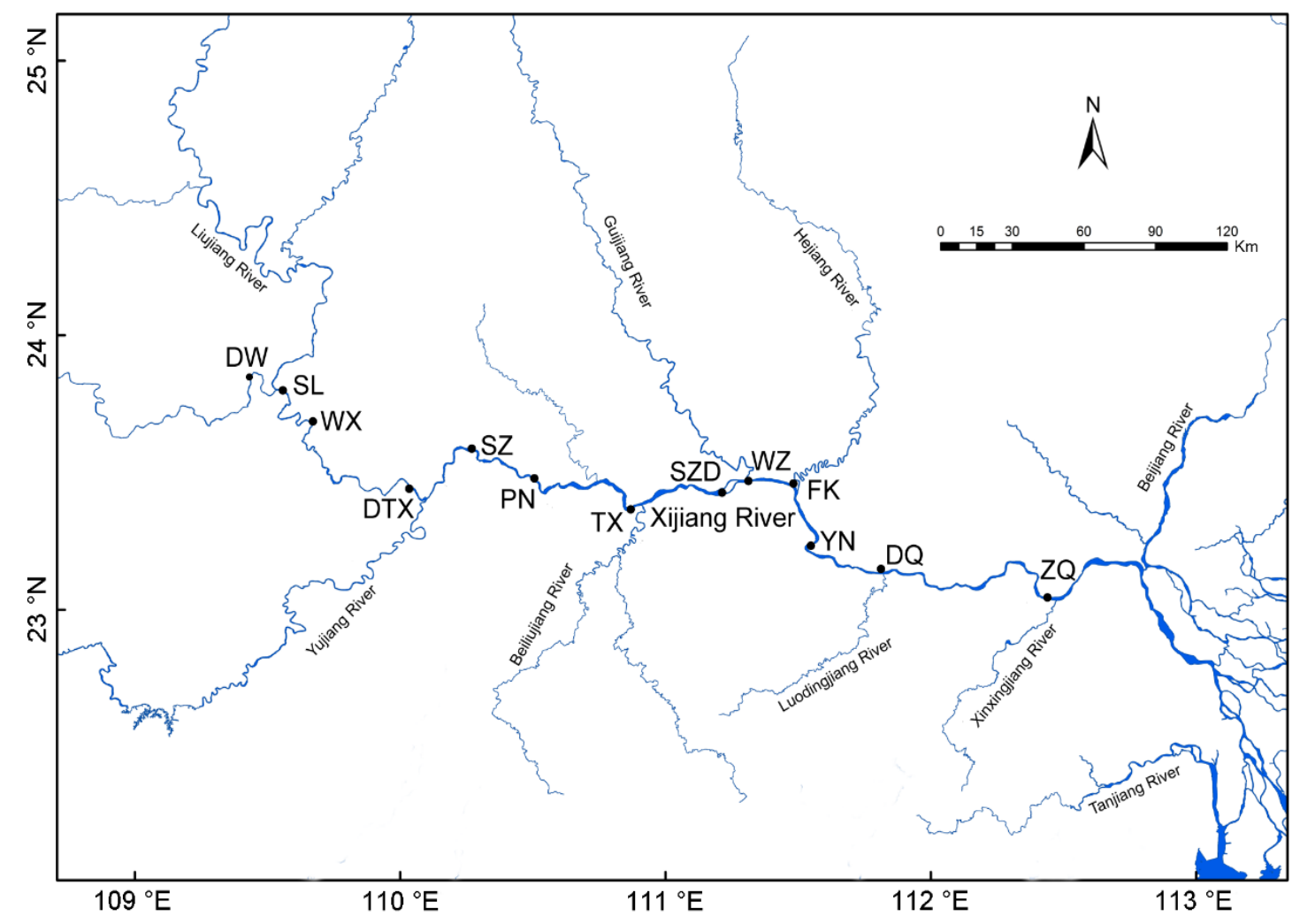

Figure 1. Distribution of sampling sites. The blue lines indicate the Xijiang River and its tributaries. The black spots are the sampling sites. DW, Dawan Town (109.469 E 23.867 N); SL, Shilong Town (109.547 E 23.780 N); WX, Wuxuan County (109.675 E 23.677 N); DTX, Datengxia (110.050 E 23.454 N); SZ, Shizui Town (110.267 E 23.586 N); PN, Pingnan County (110.498 E 23.492 N); TX, Tengxian County (110.883 E 23.374 N); SZD, Sizhoudao Island (111.214 E 23.435N); WZ, Wuzhou City (111.338 E 23.476 N); FK, Fengkai County (111.492 E 23.453 N); YN, Yunan County (111.551 E 23.240 N); DQ, Deqing County (111.789 E 23.139 N); ZQ, Zhaoqing City (112.433 E 23.047 N)

\section{DNA extraction and sequencing}

Water DNA was extracted using the MicroElute Genomic DNA kit (Omega, USA) according to the manufacturer's instructions. The total DNA was eluted in $50 \mu$ lof Elution buffer by a modification of the procedure described by manufacturer (QIAGEN, Germany) and stored at $-80{ }^{\circ} \mathrm{C}$ until used for the PCR amplification by Vazyme Biotech Co., Ltd, Nanjing, China.

The internal transcribed spacer 2 (ITS2) region of the fungus was amplified using the extracted fungal DNA as a template and the primer pair fITS7 (5'-GTGARTCATCGAATCTTTG-3') and ITS4 (5'-TCCTCCGCTTATTGATATGC- 
3') (Honkanen et al., 2020). The reaction was carried out in $25 \mu 1$ mixtures containing approximately $25 \mathrm{ng}$ of water genomic DNA, $12.5 \mu \mathrm{l}$ PCR Premix, $2.5 \mu \mathrm{l}$ of each primer $(10 \mathrm{nmol} / \mathrm{L})$, and PCR-grade water to adjust the volume. PCR reaction was performed in a Master cycler gradient thermocycler (Eppendorf, Hamburg, Germany) set to the following conditions: initial denaturation at $98{ }^{\circ} \mathrm{C}$ for $30 \mathrm{~s} ; 35$ cycles of denaturation at $98{ }^{\circ} \mathrm{C}$ for $10 \mathrm{~s}$, annealing at $54{ }^{\circ} \mathrm{C}$ for $30 \mathrm{~s}$, and extension at $72{ }^{\circ} \mathrm{C}$ for $45 \mathrm{~s}$; and then final extension at $72{ }^{\circ} \mathrm{C}$ for $10 \mathrm{~min}$. The PCR products were confirmed with $2 \%$ agarose gel electrophoresis. Ultrapure water, instead of a sample solution, was used as a negative control to exclude the possibility of false-positive PCR results. The PCR products were normalized by AxyPrep ${ }^{\mathrm{TM}}$ Mag PCR Normalizer (Axygen, CA, USA). The amplicon pools were prepared for sequencing with AMPure XT beads (Beckman Coulter Genomics, Danvers, MA, USA) and the size and quantity of the amplicon library were assessed on the LabChip GX (Perkin Elmer, Waltham, MA, USA). PhiX control library (v3) (Illumina, USA) was combined with the amplicon library (expected at 30\%). The libraries were sequenced on MiSeq platform (Illumina, USA).

The reads were filtered by quantitative insights into microbial ecology (QIIME) quality filters. The CD-HIT pipeline was used for picking operational taxonomic units (OTUs) with 97\% sequence similarity through making OTU table. Representative sequences were chosen for each OTU, and taxonomic information were assigned to each representative sequence using the Ribosomal Database Project classifier. Chao1 index (Chao, 1984), number of observed species, Shannon index, and Simpson index were the commonly used alpha-diversity indexes to measure the biodiversity of microbiota (Bucci et al., 2014; Ni et al., 2019; Xu et al., 2020). These alpha-diversity indexes were calculated using the $\mathrm{R}$ vegan package (Dixon, 2003).

\section{Data analysis}

Wilcoxon rank-sum tests were conducted using $\mathrm{R}$ software ( $\mathrm{R}$ Core Team, 2017) to compare the differences of water physical and chemical parameters, and alpha diversity indexes between the samples collected in March and those in June. Linear discriminant analysis effect size (LEfSe) was conducted through the Galaxy platform (http://huttenhower.sph.harvard.edu/galaxy/). The boxplots were plotted using R ggpubr package. RDA was conducted using $R$ vegan package. Bray-Curtis distances of the planktonic fungal communities were calculated based on OTU tables using $\mathrm{R}$ vegan package (Dixon, 2003), and Pearson's product-moment correlation analysis was conducted using $\mathrm{R}$ basicTrendline package. Results with P-values of less than 0.05 were considered significant differences.

\section{Results}

\section{Seasonal variation of water physical and chemical parameters in the Xijiang River}

Among the 16 common water physical and chemical parameters, only WT, pH, transparency, $\mathrm{TP}$, and $\mathrm{NH}_{4}-\mathrm{N}$ concentration were significantly different (Wilcoxon rank-sum test, $\mathrm{p}<0.05$ ). The $\mathrm{WT}, \mathrm{pH}$, and TP in June were significantly higher than those in March, while the transparency and $\mathrm{NH}_{4}-\mathrm{N}$ concentration were significantly lower than those in March (Fig. 2). 
(A)

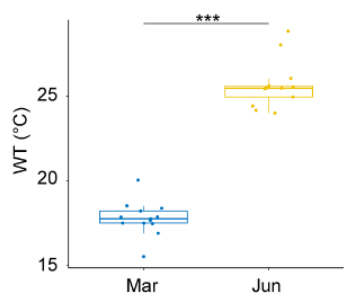

(E)

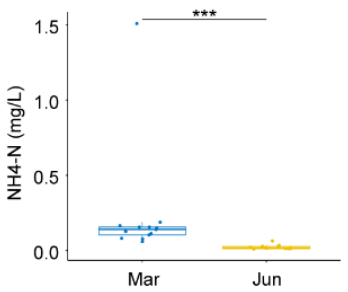

(I)

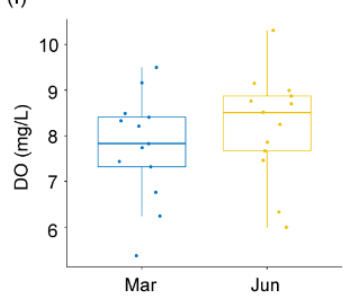

(M)

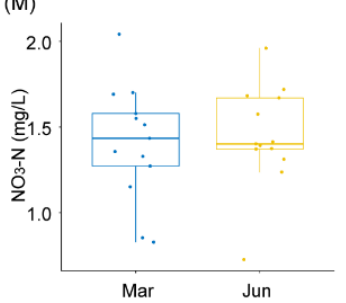

(B)

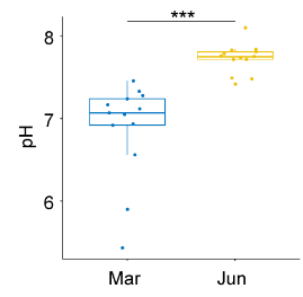

(F)

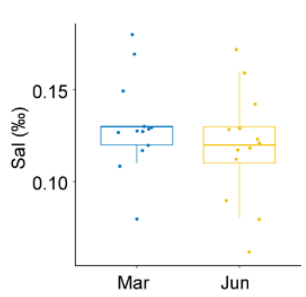

(J)

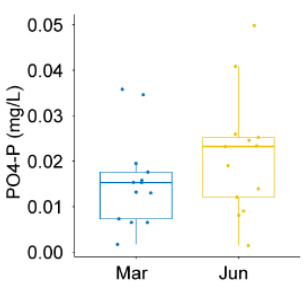

(N)

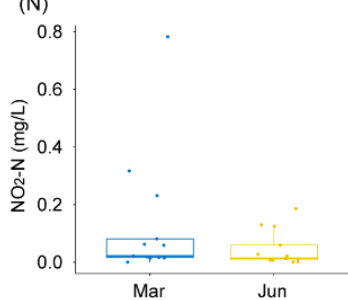

(C)

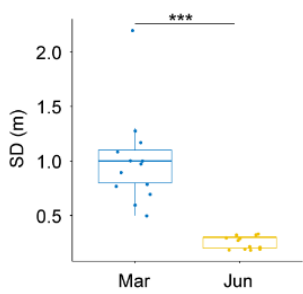

(G)

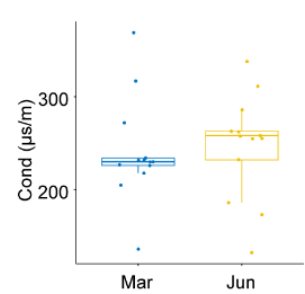

(K)

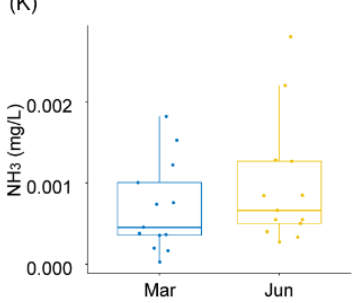

(O)

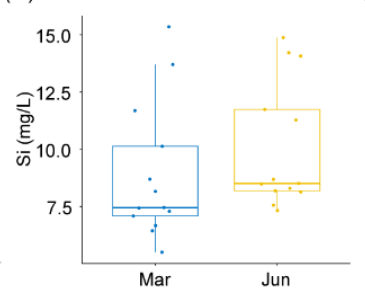

(D)

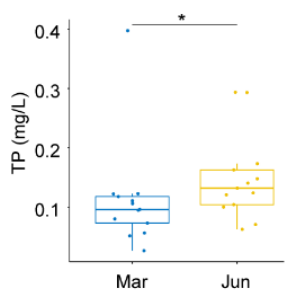

(H)

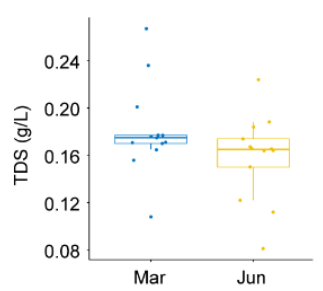

(L)

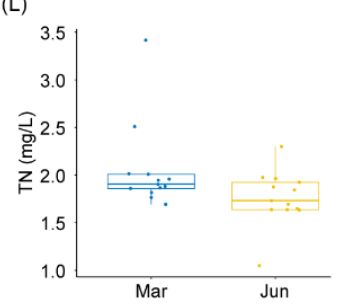

(P)

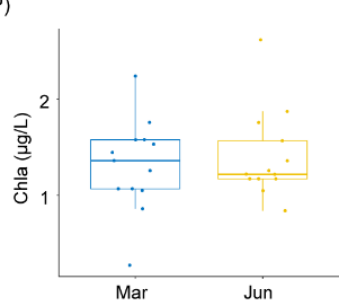

Figure 2. Differences of water physical and chemical parameters between March and June in the Xijiang River. WT, water temperature; SD, transparency; TP, total phosphorus; Sal, salinity; Cond, conductivity; TDS, total dissolved solids; DO, dissolved oxygen; TN, total nitrogen; Chla, chlorophyll-a

\section{Seasonal variation of fungal community structure in the Xijiang River}

Total 570,573 high-quality sequences were obtained from 26 samples collected in March and June. Ascomycota, Basidiomycota, Chytridiomycota, Glomeromycota, Rozellomycota, and Zygomycota were detected from the planktonic fungal communities (Fig. 3A-F). However, the number of their sequences only accounted for $40.42 \pm 0.03 \%$ of the total high-quality sequences, and most high-quality sequences $(59.58 \pm 0.03 \%)$ could not identify accurately fungal phyla (Fig. 3G). Except for Glomeromycota and Rozellomycota, the relative abundances of other phyla fluctuated more in Marth than in June (Fig. 3). Moreover, despite the existence of fluctuation between sampling sites, the relative abundance of Ascomycota increased gradually from upstream to downstream, while that of Zygomycota decreased from upstream to downstream in March (Fig. 3). 
(A)

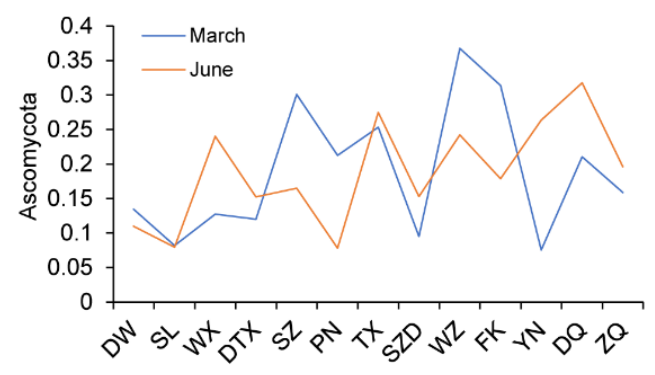

(C)

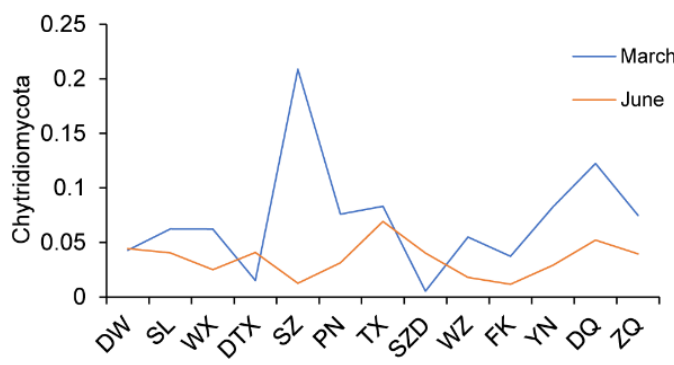

(E)

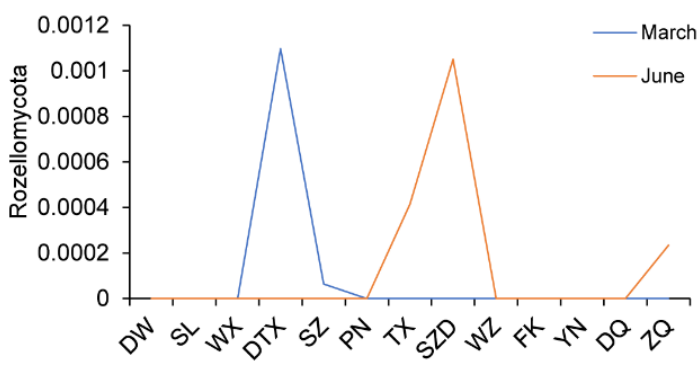

(G)

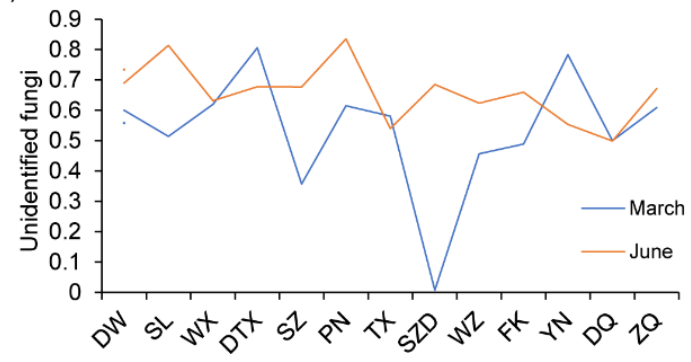

(B)

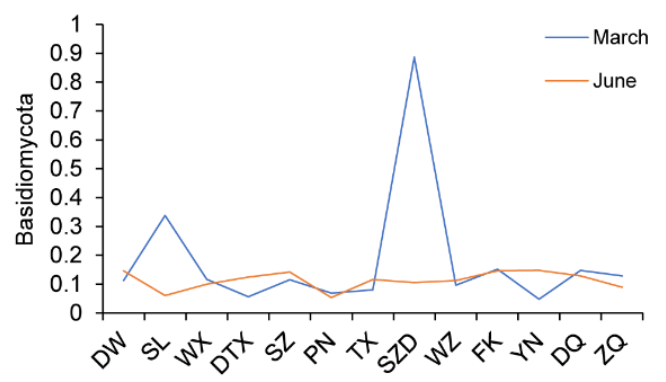

(D)

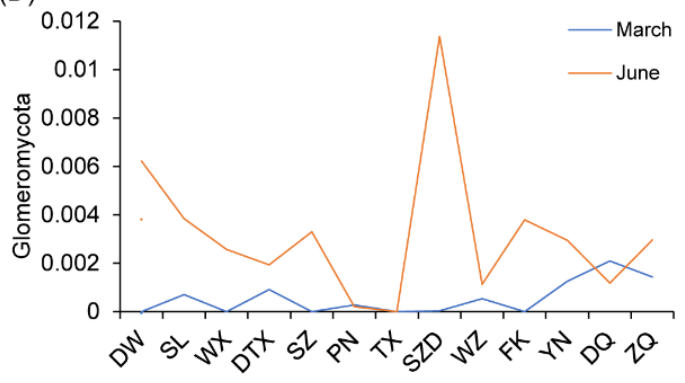

(F)

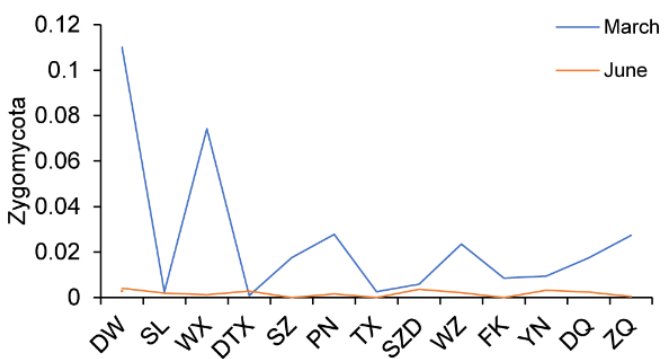

Figure 3. Relative abundance changes of fungal phyla in the water of the Xijiang River. DW, Dawan Town (109.469 E 23.867 N); SL, Shilong Town (109.547 E 23.780 N); WX, Wuxuan County (109.675 E 23.677 N); DTX, Datengxia (110.050 E 23.454 N); SZ, Shizui Town (110.267 E 23.586 N); PN, Pingnan County (110.498 E 23.492 N); TX, Tengxian County (110.883 E 23.374 N); SZD, Sizhoudao Island (111.214 E 23.435N); WZ, Wuzhou City (111.338 E 23.476 N); FK, Fengkai County (111.492 E 23.453 N); YN, Yunan County (111.551 E 23.240 N); DQ, Deqing County (111.789 E 23.139 N); ZQ, Zhaoqing City (112.433 E 23.047 N)

Although there was no significant difference in the number of OTUs detected in the planktonic fungal communities in March and June, the Shannon, Simpson, and Chao1 indexes of the fungal communities in June were significantly higher than those in March (Wilcoxon rank-sum test, $\mathrm{p}<0.05 ;$ Fig. 4). 
(A)

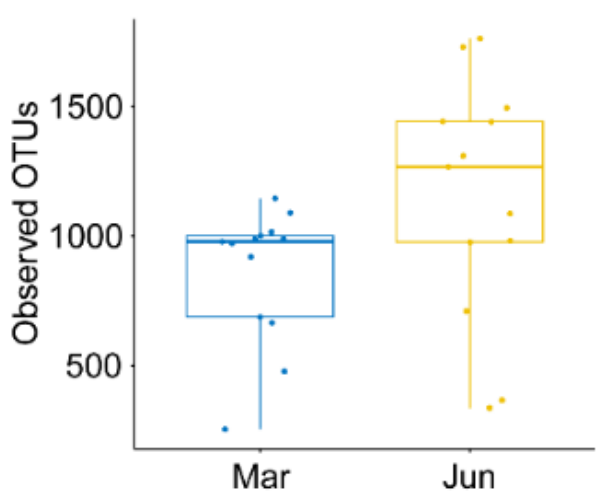

(C)

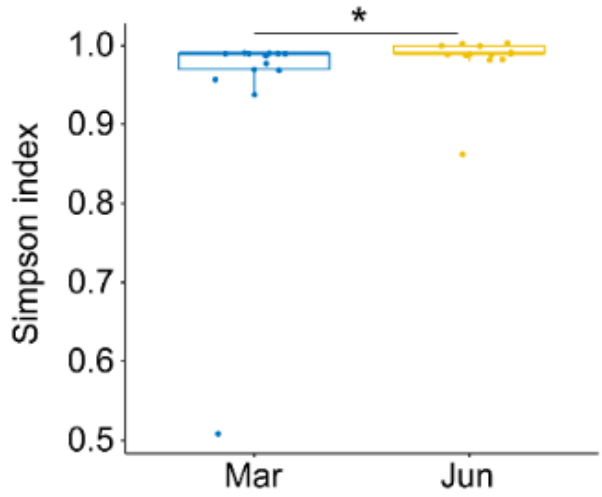

(B)

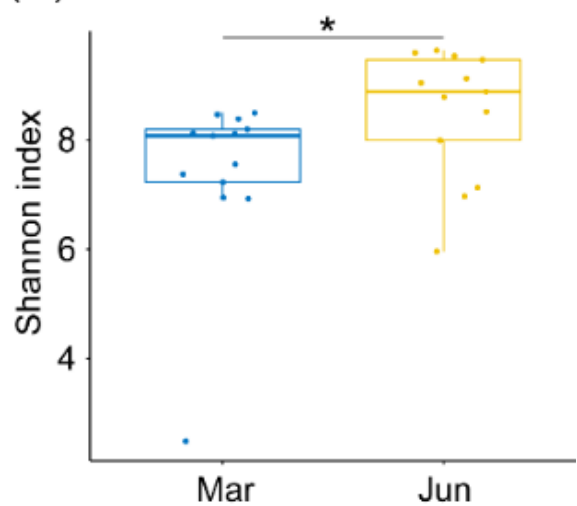

(D)

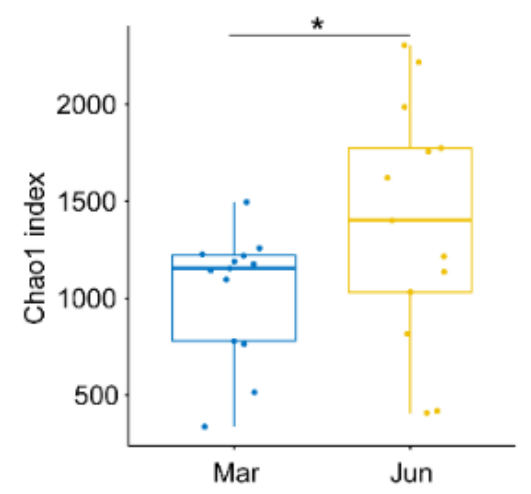

Figure 4. Comparison of $\alpha$-diversity indexes of planktonic fungal communities between March and June in the Xijiang River

In the dominant fungi that were identified to species level, the relative abundances of Phoma brasiliensis, Pseudozyma sp., Psathyrella sp., Haematonectria haematococca, Podoscypha sp. in the fungal in June were significantly higher than those in March, while the relative abundances of Basidiobolus sp., Rhizophydium littoreum, Teratosphaeria jonkershoekensis, Malassezia globosa, Malassezia restricta, Malassezia sp., Alternaria eichhorniae, Knufia epidermidis, and Scedosporium prolificans were significantly lower (LEfSe, LDA > 2; Fig. 5).

To analyze the dispersal limitation of planktonic fungal communities in the river and analyze the impact of water environmental parameters on the planktonic fungal community structure, we analyzed the relationship between the Bray-Curtis distances of planktonic fungal communities and geographical distances by correlation analysis, and the relationship between water environmental parameters and planktonic fungal community structure using RDA. Our results showed that no significant correlation between fungal community distance and geographical distance along the river (Pearson's product-moment correlation, $\mathrm{p}>0.05 ;$ Fig. 6 A and B). Although no water environmental parameter significantly influenced the fungal community structure in March, WT and DO significantly influenced the fungal community structure in June (Fig. 6C and 6D). 


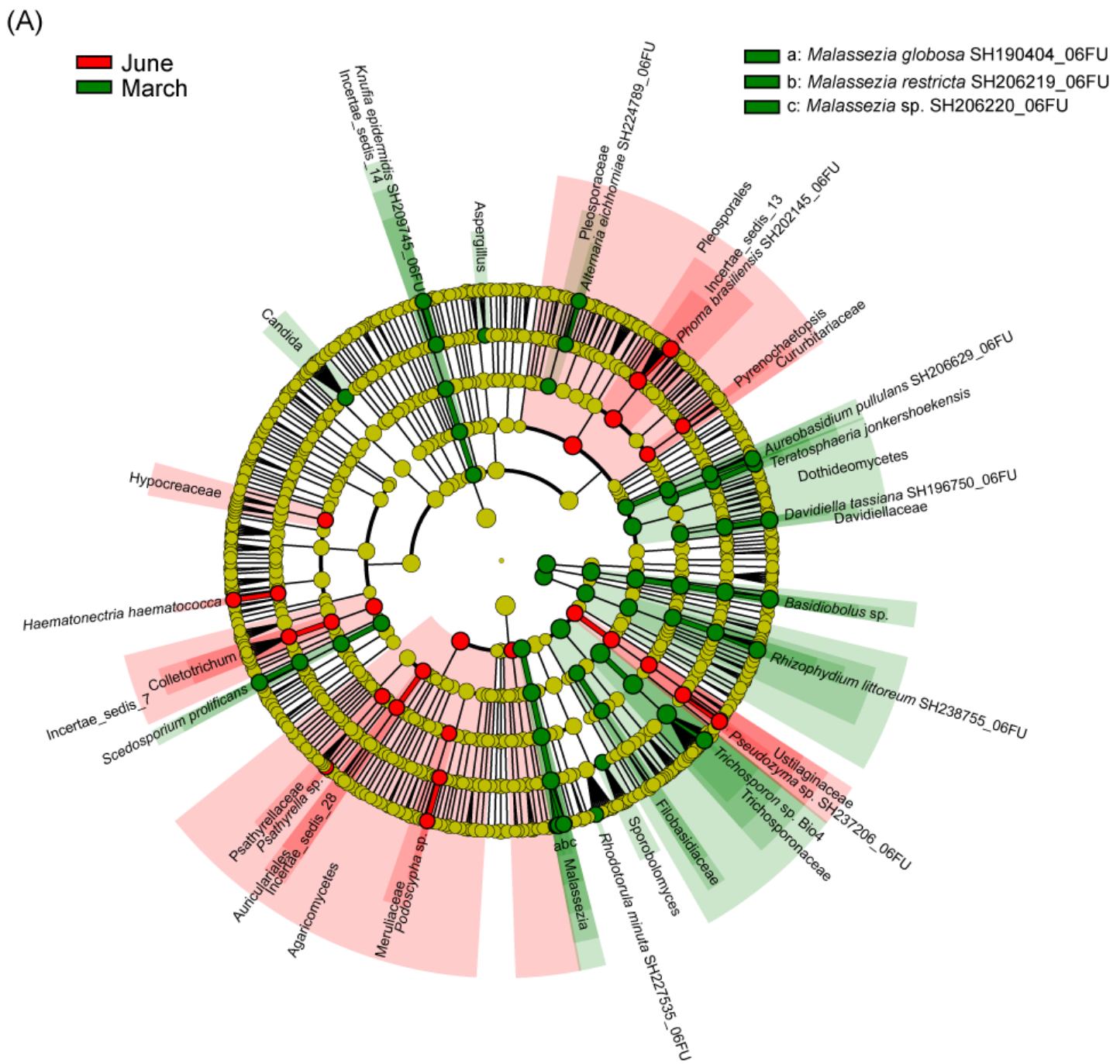

(B)

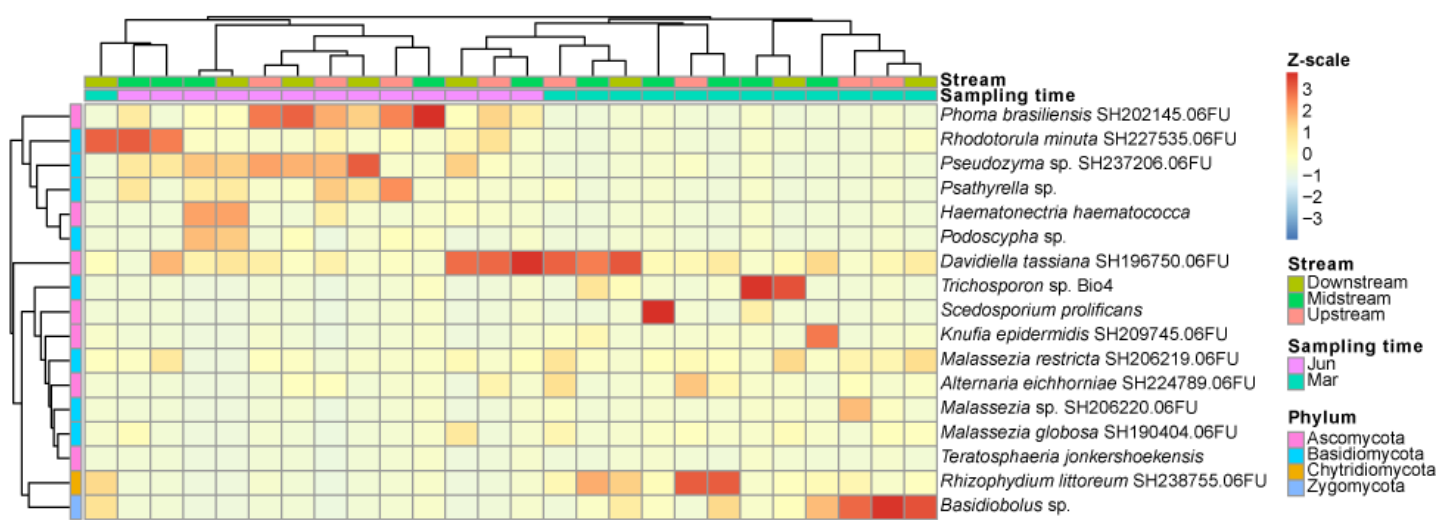

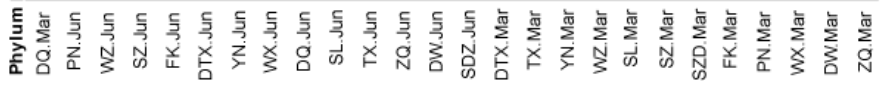

Figure 5. Cladogram plot of Linear discriminant analysis effect size (LEfSe) (A) and heatmap profile of significantly different fungal species $(B)$ between the samples collected in March and 
(A)

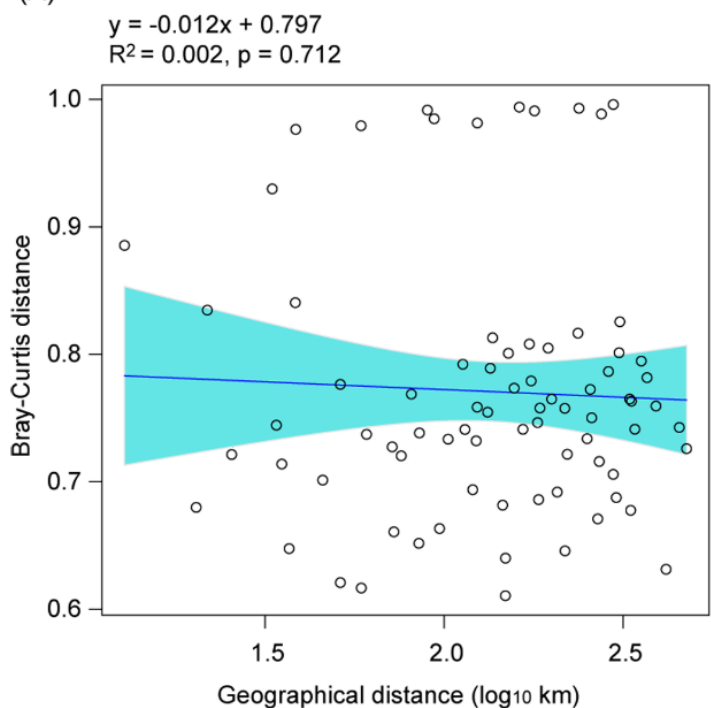

(C)

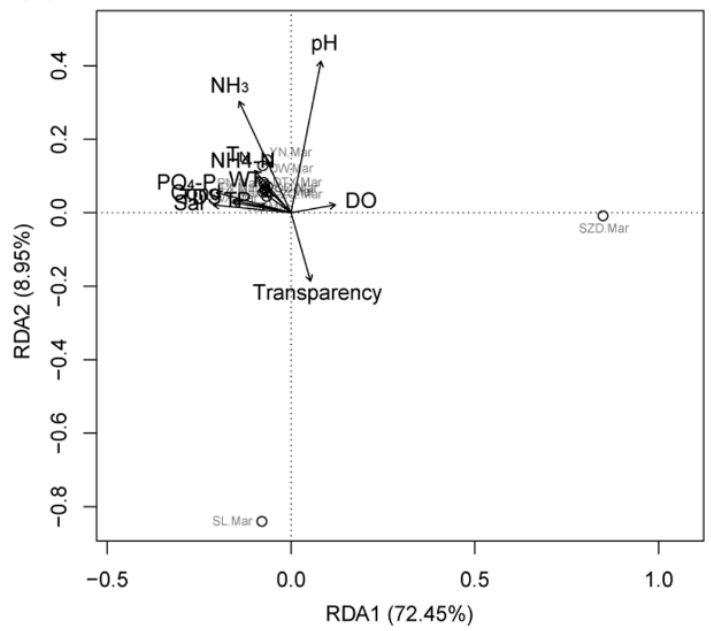

(B)

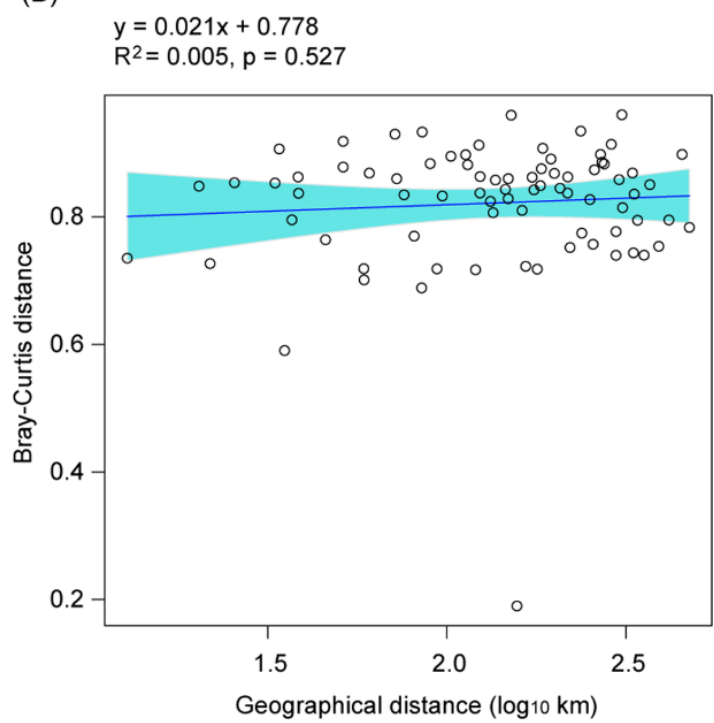

(D)

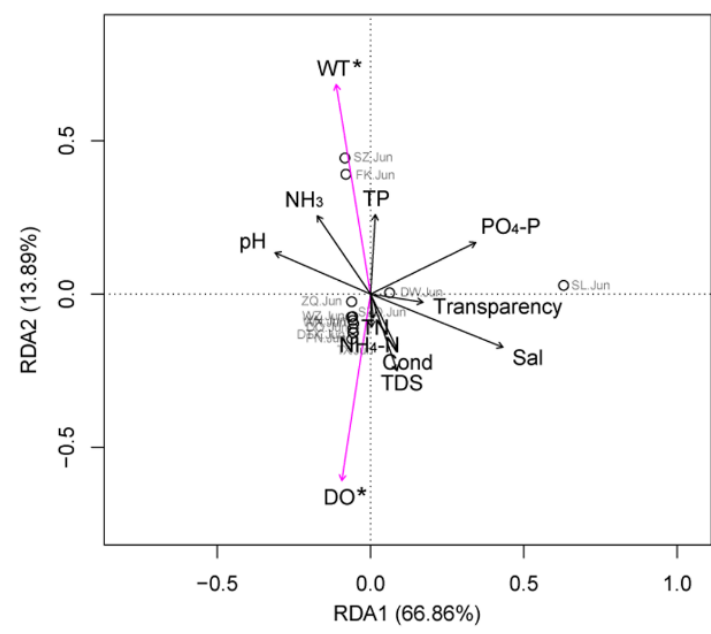

Figure 6. Correlation between fungal community distance and geographical distance along the river in March (A) and June (B), and RDA profiles showed the relationship of water physical and chemical parameters and planktonic fungal community structures in the samples collected in March (C) and June (D). WT, water temperature; TP, total phosphorus; Sal, salinity; Cond, conductivity; TDS, total dissolved solids; DO, dissolved oxygen; TN, total nitrogen; Chla, chlorophyll-a. *, $p<0.05$

\section{Discussion}

Panzer et al. (2015) summarized the research on environmental fungal communities based on 18S rRNA gene, and found that Ascomycota, Basidiomycota, and Chytridiomycota are the main components of freshwater fungal communities. In this study, we found that although Ascomycota, Basidiomycota, Chytridiomycota, Glomeromycota, Rozellomycota, and Zygomycota were detected from the planktonic fungal communities, the number of their sequences only accounted for $40.42 \pm 0.03 \%$ of the total high-quality sequences. This result implied that there were a large number of fungal species that had not been studied in detail. Moreover, compared with bacterial community compositions of freshwater and sediment, the results of our analysis on the 
compositions of fungal communities in the Xijiang River were similar to those in the sediment of a lake - Ascomycota, Basidiomycota, and Chytridiomycota had the highest abundance (Wang et al., 2018a). Among them, Chytridiomycota mainly feeds on dead aquatic plants or other detritus in water, and the released zoospores are preyed by zooplankton, which plays an important role in the food web of water (Kagami et al., 2014).

The community structure of planktonic fungi has been shown to be affected by $\mathrm{pH}$, WT, and conductivity, as well as the physical and chemical properties of the organic matter, such as nitrogen and phosphorus (Cudowski et al., 2015; Reich et al., 2017). However, our results showed that only WT and DO had significant effects on the community structure of planktonic fungi in the high-water period (Fig. 6C and D). This might be because the physical and chemical indicators of various sampling sites in the river had little difference (Fig. 2), thus eliminating the impact of physical and chemical parameters on the composition of river fungal communities. Therefore, it is necessary to investigate the community compositions of phytoplankton fungi in river at a larger time and space scale with wider range of differences in physical and chemical parameters in the future.

Dispersal limitation is considered an important factor that influences the $\beta$-diversity of microbiota, which is mainly reflected in the fact that the distance of microbiota increases with the increase in geographical distance (Ni et al., 2014; Cao et al., 2016; Logares et al., 2020). Due to the weak active dispersal ability of microorganisms, it usually presents a trend of dispersal limitation (Shurin, 2000; Peay et al., 2010; Chytrý et al., 2012; Ni et al., 2014; Beaton et al., 2016). However, our results showed no significant correlation between fungal community distance and geographical distance along the river. These results indicated that planktonic fungal communities eliminated the deficiency in active dispersal through passive dispersal of river water flow, which eliminated the dispersal limitation of the planktonic fungal communities in rivers.

\section{Conclusion}

Ascomycota, Basidiomycota, Chytridiomycota, Glomeromycota, Rozellomycota, and Zygomycota were detected from the planktonic fungal communities. However, the number of their sequences only accounted for $40.42 \pm 0.03 \%$ of the total high-quality sequences. Shannon, Simpson, and Chaol indexes of the fungal communities in the highwater period were significantly higher than those in the low-water period. The relative abundances of Phoma brasiliensis, Pseudozyma sp., Psathyrella sp., Haematonectria haematococca, Podoscypha sp. in the high-water period were significantly higher than those in the low-water period, while the relative abundances of Basidiobolus sp., Rhizophydium littoreum, Teratosphaeria jonkershoekensis, Malassezia globosa, Malassezia restricta, Malassezia sp., Alternaria eichhorniae, Knufia epidermidis, and Scedosporium prolificans were significantly lower. No significant correlation between the fungal community distance and geographical distance along the river. Water temperature and dissolved oxygen significantly influenced the fungal community structure in the high-water period. However, it is necessary to investigate the community compositions of phytoplankton fungi in river at a larger time and space scale in the future, and more freshwater phytoplankton fungi were needed to study through culturing method and their genomic database was needed to supplement. In addition, the relationship among planktonic fungi, bacteria, and multicellular organisms still needs to further study. 
Acknowledgements. This study was supported by the Central Public-interest Scientific Institution Basal Research Fund, CAFS (Grant No. 2020ZJTD-05 and 2017HY-ZC0704), the National Key R\&D Program of China Fund (Grant No. 2018YFD0900802), and the Key Lab of Freshwater Biodiversity Conservation Ministry of Agriculture and Rural Affairs Research Fund (Grant No. LFBC0909). We wish to thank Dr. Jiajia Ni, a technician at Guangdong Meilikang Bio-Sciences Ltd., China for his help in analyzing the microbial data.

\section{REFERENCES}

[1] Bärlocher, F., Boddy, L. (2016): Aquatic fungal ecology - How does it differ from terrestrial? - Fungal Ecology 19: 5-13.

[2] Beaton, E. D., Stevenson, B. S., King-Sharp, K. J., Stamps, B. W., Nunn, H. S., Stuart, M. (2016): Local and regional diversity reveals dispersal limitation and drift as drivers for groundwater bacterial communities from a fractured granite formation. - Frontiers in Microbiology 7: 1933.

[3] Broeckling, C. D., Broz, A. K., Bergelson, J., Manter, D. K., Vivanco, J. M. (2008): Root exudates regulate soil fungal community composition and diversity. - Applied and Environmental Microbiology 74(3): 738-744.

[4] Bucci, J. P., Szempruch, A. J., Caldwell, J. M., Ellis, J. C., Levine, J. F. (2014): Seasonal changes in microbial community structure in freshwater stream sediment in a North Carolina River Basin. - Diversity 6: 18-32.

[5] Cai, L., Ji, K. F., Hyde, K. D. (2006): Variation between freshwater and terrestrial fungal communities on decaying bamboo culms. - Antonie Van Leeuwenhoek 89(2): 293-301.

[6] Cao, P., Wang, J. T., Hu, H. W., Zheng, Y. M., Ge, Y., Shen, J. P., He, J. Z. (2016): Environmental filtering process has more important roles than dispersal limitation in shaping large-scale prokaryotic beta diversity patterns of grassland soils. - Microbial Ecology 72: 221-230.

[7] Carson, C. M., Jumpponen, A., Blair, J. M., Zeglin, L. H. (2019): Soil fungal community changes in response to long-term fire cessation and $\mathrm{N}$ fertilization in tallgrass prairie. Fungal Ecology 41: 45-55.

[8] Chao, A. (1984): Non-parametric estimation of the number of classes in a population. Scandinavian Journal of Statistics 11: 265-270.

[9] Chen, Z., Yuan, J., Sun, F., Zhang, F., Chen, Y., Ding, C., Shi, J., Li, Y., Yao, L. (2018): Planktonic fungal community structures and their relationship to water quality in the Danjiangkou Reservoir, China. - Scientific Reports 8: 10596.

[10] Chung, N., Suberkropp, K. (2008): Influence of shredder feeding and nutrients on fungal activity and community structure in headwater streams. - Fundamental and Applied Limnology 173(1): 35-46.

[11] Chytrý, M., Lososová, Z., Horsák, M., Uher, B., Čejka, T., Danihelka, J., Fajmon, K., Hájek, O., Jư̌ričková, L., Kintrová, K., Láníková, D., Otýpková, Z., Řehořek, V., Tichý, L. (2012): Dispersal limitation is stronger in communities of microorganisms than macroorganisms across Central European cities. - Journal of Biogeography 39: 1101-1111.

[12] Cudowski, A., Pietryczuk, A., Hauschild, T. (2015): Aquatic fungi in relation to the physical and chemical parameters of water quality in the Augustów Canal. - Fungal Ecology 13: 193204.

[13] Dixon, P. (2003): VEGAN, a package of R functions for community ecology. - Journal of Vegetation Science 14: 927-930.

[14] Gao, Q., Tao, Z., Shen, C., Sun, Y., Yi, W., Xing, C. (2002): Riverine organic carbon in the Xijiang River (South China): seasonal variation in content and flux budget. - Environmental Geology 41: 826-832. 
[15] Gao, Z., Johnson, Z. I., Wang, G. Y. (2010): Molecular characterization of the spatial diversity and novel lineages of mycoplankton in Hawaiian coastal waters. - The ISME Journal 4: 111-120.

[16] Grattan, R. M. II, Suberkropp, K. (2001): Effects of nutrient enrichment on yellow poplar leaf decomposition and fungal activity in streams. - Journal of the North American Benthological Society 20: 33-43.

[17] Gulis, V., Suberkropp, K. (2003): Leaf litter decomposition and microbial activity in nutrientenriched and unaltered reaches of a headwater stream. - Freshwater Biology 48: 123-134.

[18] Gutierrez, M. H., Pantoja, S., Tejos, E., Quinones, R. A. (2011): The role of fungi in processing marine organic matter in the upwelling ecosystem off Chile. - Marine Biology 158: 205-219.

[19] Honkanen, J., Vuorela, A., Muthas, D., Orivuori, L., Luopajärvi, K., Vishakante, M., Tejesvi, G., Lavrinienko, A., Pirttilä, A. M., Fogarty, C. L., Härkönen, T., Ilonen, J., Ruohtula, T., Knip, M., Koskimäki, J. J., Vaarala, O. (2020): Fungal dysbiosis and intestinal inflammation in children with beta-cell autoimmunity. - Fronters in Immunology 11: 468.

[20] Hopkins, J. M., Marcarelli, A. M., Bechtold, H. A. (2011): Ecosystem structure and function are complementary measures of water quality in a polluted, spring-influenced river. - Water Air and Soil Pollution 214: 409-421.

[21] Huang, X. F. (2000): Survey, Observation and Analysis of Lake Ecology. - China Standard Press, Beijing.

[22] Kaevska, M., Videnska, P., Sedlar, K., Slana, I. (2016): Seasonal changes in microbial community composition in river water studied using 454-pyrosequencing. - SpringerPlus 5: 409.

[23] Kagami, M., Amano, Y., Ishii, N. (2012): Community structure of planktonic fungi and the impact of parasitic chytrids on phytoplankton in Lake Inba, Japan. - Microbial Ecology 63: 358-368.

[24] Kagami, M., Miki, T., Takimoto, G. (2014): Mycoloop: chytrids in aquatic food webs. Frontiers in Microbiology 5: 166.

[25] Kent, A. D., Bayne, Z. L. (2010): Degraded water quality influences microbial community composition and perception of health risks in the Chattooga River. - DNA and Cell Biology 29(9): 509-517.

[26] Lance, A. C., Burke, D. J., Hausman, C. E., Burns, J. H. (2020): High-throughput sequencing provides insight into manipulated soil fungal community structure and diversity during temperate forest restoration. - Restoration Ecology 28(S4): S365-S372.

[27] Li, J., Li, X., Tan, X., Li, Y., He, M., Luo, J., Lin, J., Su, S. (2009): Species diversity of fish community of Provincial Xjiang River Rare Fishes Natural Reserve in Zhaoqing City, Guangdong Province. - Journal of Lake Sciences 21(4): 556-562.

[28] Li, J., Li, X., Jia, X., Li, Y., He, M., Tan, X., Wang, C., Jiang, W. (2010): Evolvement and diversity of fish community in Xijiang River. - Journal of Fishery Sciences of China 17(2): 298-311.

[29] Logares, R., Deutschmann, I. M., Junger, P. C., Giner, C. R., Krabberød, A. K., Schmidt, T. S. B., Rubinat-Ripoll, L., Mestre, M., Salazar, G., Ruiz-González, C., Sebastián, M., de Vargas, C., Acinas, S. G., Duarte, C. M., Gasol, J. M., Massana, R. (2020): Disentangling the mechanisms shaping the surface ocean microbiota. - Microbiome 8: 55.

[30] Maksimenko, S. Y., Zemskaya, T. I., Pavlova, O. N., Ivanov, V. G., Buryukhaev, S. P. (2008): Microbial community of the water column of the Selenga River-Lake Baikal biogeochemical barrier. - Microbiology 77(5): 587-594.

[31] Mueller, R. C., Belnap, J., Kuske, C. R. (2015): Soil bacterial and fungal community responses to nitrogen addition across soil depth and microhabitat in an arid shrubland. Frontiers in Microbiology 6: 891.

[32] Ni, J., Yu, Y., Feng, W., Yan, Q., Pan, G. (2010): Impacts of algal blooms removal by chitosan-modified soils on zooplankton community in Taihu Lake, China. - Journal of Environmental Sciences 22(10): 1500-1507. 
[33] Ni, J., Yan, Q., Yu, Y., Zhang, T. (2014): Fish gut microecosystem: a model for detecting spatial pattern of microorganisms. - Chinese Journal of Oceanology and Limnology 32(1): 54-57.

[34] Ni, J., Huang, R., Zhou, H., Xu, X., Li, Y., Cao, P., Zhong, K., Ge, M., Chen, X., Hou, B., Yu, M., Peng, B., Li, Q., Zhang, P., Gao, Y. (2019): Analysis of the relationship between the degree of dysbiosis in gut microbiota and prognosis at different stages of primary hepatocellular carcinoma. - Frontiers in Microbiology 10: 1458.

[35] Panzer, K., Yilmaz, P., Weiß, M., Reich, L., Richter, M., Wiese, J., Schmaljohann, R., Labes, A., Imhoff, J. F., Glöckner, F. O., Reich, M. (2015): Identification of habitat-specific biomes of aquatic fungal communities using a comprehensive nearly full-length $18 \mathrm{~S}$ rRNA dataset enriched with contextual data. - PLoS ONE 10(7): e134377.

[36] Peay, K. G., Garbelotto, M., Bruns, T. D. (2010): Evidence of dispersal limitation in soil microorganisms: Isolation reduces species richness on mycorrhizal tree islands. - Ecology 91(12): 3631-3640.

[37] R Core Team. (2017): R: A language and environment for statistical computing. - R Foundation for Statistical Computing, Vienna, Austria. URL https://www.R-project.org/.

[38] Reich, M., Wichels, A., Panzer, K., Krause, E., Giménez, L., Gerdts, G. (2017): Impacts of a reduction in seawater $\mathrm{pH}$ mimicking ocean acidification on the structure and diversity of mycoplankton communities. - Aquatic Microbial Ecology 79: 221-233.

[39] Röske, K., Sachse, R., Scheerer, C., Röske, I. (2012): Microbial diversity and composition of the sediment in the drinking water reservoir Saidenbach (Saxonia, Germany). - Systematic and Applied Microbiology 35(1): 35-44.

[40] Shang, P., Chen, S., Huang, T., Zhang, H., Kang, P., Wang, Y., Zhao, Z., Liu, T. (2018): Vertical distribution of fungal community composition and water quality during the deep reservoir thermal stratification. - Environmental Science 39(3): 1141-1150.

[41] Shurin, J. B. (2000): Dispersal limitation, invasion resistance, and the structure of pond zooplankton communities. - Ecology 81(11): 3074-3086.

[42] Sui, X., Zhang, R., Xu, N., Liu, Y., Chai, C., Wang, J., Fu, X., Zhong, H., Ni, H. (2016): Fungal community structure of different degeneration Deyeuxia angustifolia wetlands in Sanjiang Plain. - Environmental Science 37(9): 3598-3605.

[43] The State Environmental Protection Administration. (2002): Water and wastewater monitoring and analysis method (Fourth edition). - China Environmental Science Press, Beijing.

[44] Wang, P., Xiao, H. Y., Yuan, R. Q., Zhao, J., Yu, X. F. (2018a): Fungal community in the estuarine sediment of Poyang Lake. - Acta Scientiae Circumstantiae 38(5): 1949-1956.

[45] Wang, L., Zhang, J., Li, H., Yang, H., Peng, C., Peng, Z., Lu, L. (2018b): Shift in the microbial community composition of surface water and sediment along an urban river. Science of the Total Environmental 627: 600-612.

[46] Wu, B., Tiao, J., Bai, C., Xiang, M., Sun, J., Liu, X. (2013): The biogeography of fungal communities in wetland sediments along the Changjiang River and other sites in China. The ISME Journal 7: 1299-1309.

[47] Xu, B., Yan, Y., Huang, J., Yin, B., Pan, Y., Ma, L. (2020): Cortex phelodendri extract's anti-diarrhea effect in mice related to its modification of gut microbiota. - Biomedicine \& Pharmacotherapy 123: 109720.

[48] Yu, L., Zhang, W., Liu, L., Yang, J. (2015): Determining microeukaryotic plankton community around Xiamen island, southeast China, using Illumina MiSeq and PCR-DGGE techniques. - PLoS ONE 10(5): e0127721.

[49] Zhang, H. H., Huang, T. L., Chen, S. N., Guo, L., Liu, T. T. (2013): Spatial pattern of bacterial community functional diversity in a drinking water reservoir, Shaanxi Province, Northwest China. - Journal of Pure and Applied Microbiology 7(3): 1647-1654.

[50] Zou, L. Y., Cheng, X. C. (2002): Water quality evaluation index and conversion method of UIA. - Fisheries Science 21(2): 42-43. 